\title{
Manipulating apparent duration with simultaneous effects on memory
}

\author{
DONALD J. POLZELLA, SAMUEL M. BOWER, and ALLEN S. GOUSE \\ University of Dayton, Dayton, Ohio 45469
}

\begin{abstract}
This experiment explored the relationship between perceived time and memory. One hundred and forty-four subjects viewed a list of 30 words under one of three conditions. The conditions were designed to induce differences in the perceived duration of the words by varying the number of incidental stimuli during the period just before each word was visible. After viewing the list, all subjects estimated the duration of each word, the number of words, and the duration of the list. Following this, subjects attempted to recognize the words among 50 distractors. It was found that increases in memory accompanied increases in perceived duration. The results were consistent with the hypothesis that changes in time perception and memory are mediated by changes in attention.
\end{abstract}

Beginning with Ebbinghaus, experimental psychologists have considered memory to be a function of the time elapsed between the occurrence of an event and its retrieval. However, recent research suggests that time can be properly treated as a psychological variable. It has been repeatedly demonstrated that as the amount of information processed during an interval changes, the duration of the interval also changes (Avant, Lyman, \& Antes, 1975; Hicks, Miller, \& Kinsbourne, 1976; Miller, Hicks, \& Willette, 1978; Thomas \& Cantor, 1976). But few studies have explored the relationship between perceived time and memory. Since perceived duration is related to changes in cognitive activity, perceived duration may also be related to changes in memory.

There is some evidence that this is so. In two experiments, Block (1974) found that long-term recognition memory for words presented within an interval varied positively with the apparent duration of that interval. In both experiments, the apparent duration of an interval filled with words was compared to the apparent duration of a standard interval, and a series of memory tests followed. In the first experiment, words were presented auditorily during a $180-\mathrm{sec}$ interval at a rate of either 30 words/180 sec or 60 words/180 sec. In the second experiment, 80 categorized words were visually presented during a 160 -sec interval in either random or blocked order. In the first experiment, the perceived duration of the 60 -word interval exceeded the perceived duration of the 30-word interval, and more of the 60 words were correctly recognized. In the second experiment, the perceived duration of the blocked words exceeded the perceived duration of the random words, and more blocked words were correctly remembered.

These data were presented at the meeting of the American Psychological Association, New York, September 1979. Requests for reprints should be sent to D. J. Polzella, Department of Psychology, University of Dayton, Dayton, Ohio 45469.
Block (1974) concluded that the apparent duration of an interval in retrospect is "based on" the number of events stored during and retrieved from that interval. But alternative conclusions are possible, namely, (1) that the number of events stored and retrieved from an interval is based on the apparent duration of that interval or (2) that apparent duration and memory are correlated but not causally related. Block's design does not permit an assessment of these alternatives because he manipulated apparent duration by varying the to-beremembered material itself. This confound has been eliminated in the present experiment by manipulating the temporal distribution of incidental material while keeping the to-be-remembered material constant.

\section{METHOD}

\section{Subjects}

The subjects were 144 introductory psychology students at the University of Dayton. They volunteered for this experiment in order to fulfill a research requirement.

\section{Stimuli}

The to-be-remembered material was a list of 30 common four-letter nouns. The words were presented serially, on $8-\mathrm{mm}$ movie film, at a 5-sec rate. Each word was preceded by a 4.5 -sec series of 10 black rectangular frames, which appeared in the center of the screen on which the word would be presented. Three films, which differed only in the temporal distribution of the frames, were used in the experiment. In the accelerating film, the frames appeared at a logarithmically increasing rate. In the constant film, they appeared at a constant rate. And in the decelerating film, they appeared at a logarithmically decreasing rate. The three films were designed to induce differences in the perceived duration of the words by varying the number of events (frames) during the period just before a word was visible. Perceived duration is usually an increasing function of the number of stimuli that occur during an interval (see Hicks et al., 1976).

\section{Procedure}

The subjects were tested in small groups (5-10), which were randomly assigned to view one of the three films. After viewing the film, the subjects completed the following: First, 
they graphically estimated the apparent duration of each word relative to each frame sequence. Specifically, they were shown a $100-\mathrm{mm}$ horizontal line and told to mark the line at a point that divided it into "the time you believe you were watching the sequence of frames (to the left of the mark) and the time you believe you were watching the word (to the right of the mark)." Second, they estimated the total time of the film in minutes and seconds. Third, they estimated the number of words seen. Finally, they attempted to recognize the words among 50 distractors. The subjects were not informed of these tasks until after they viewed the film.

\section{RESULTS}

The experimental condition had a significant effect on recognition $[F(2,141)=3.26, p<.05]$ and a significant effect on the perceived duration of the words $[F(2,141)=3.34, p<.05]$. Both of these effects are shown in Figure 1, in which the corrected proportion of words recognized and the perceived duration of the words (in millimeters) are plotted as functions of the film viewed. In general, both functions increase as the number of incidental events just before the words increases. [The lack of monotonicity in the perceived duration function may be an artifact of the graphic estimation scale. Schiffman and Bobko (1978) found that most subjects avoid the extremes when asked to partition a $100-\mathrm{mm}$ horizontal line into the "most pleasing" ratio or shortest to longest line segments.] Subjects typically underestimated both the duration of the film and the number of words seen, but there were no differences among the three experimental groups on either of these variables $(\mathrm{Fs}<1.00)$.

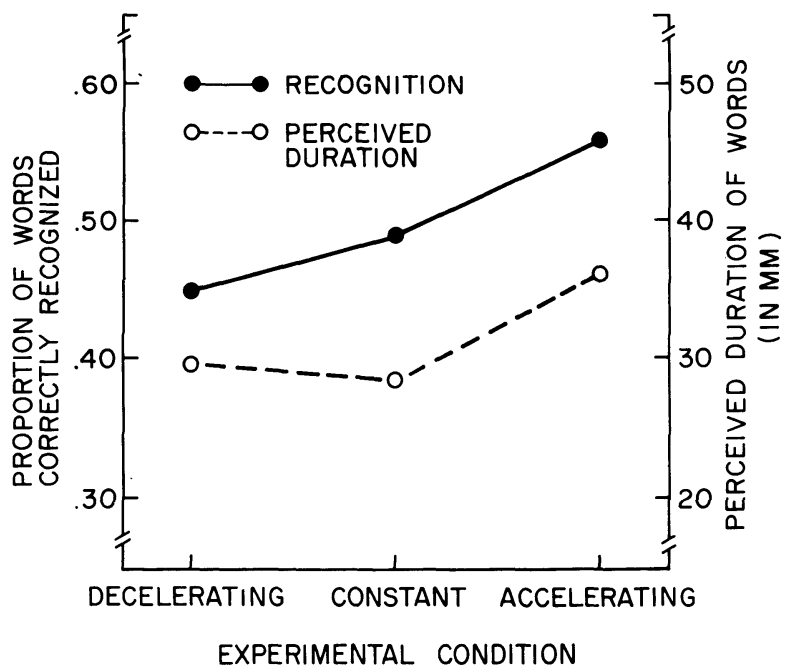

Figure 1. The proportion of words correctly recognized and the perceived duration of words as a function of experimental condition.

\section{DISCUSSION}

The results of this experiment show that differences in recognition memory for words accompany differences in the perceived duration of those words. In general, increases in memory are associated with increases in apparent duration. These results support Block's (1974) findings. However, in the present experiment, differences in perceived duration were induced without varying the to-be-remembered material. It may be that the perceived duration of the words was "based on" the number of words remembered, but a more parsimonious explanation suggests that increasing the apparent time a word is visible increases the recallability of that word. Support for this explanation comes from Krauss, Katzell, and Krauss (1974), who were able to enhance free recall learning by hypnotic time distortion (i.e., by suggesting that $3 \mathrm{~min}$ of study time was equivalent to $10 \mathrm{~min}$ ), and from Pomerantz, Goldberg, Golder, and Tetewsky (1981), who found that the presence of subjective (i.e., illusory) contours can facilitate visual information processing.

The relationship between apparent time and memory is manifested during both encoding and storage. In the present experiment, we found that memory was increased when the perceived duration of the to-be-remembered material was increased. In a previous study, Gouse, Polzella, Biers, and Bower (Note 1) found that memory was inversely related to the perceived duration of the retention interval. These effects were also observed by Underwood (1975), who used a design similar to Block's (1974). Underwood (1975) suggested that changes in time perception and memory are mediated by changes in the level of attention. In the present experiment, this would mean that the accelerating frame sequence increased the subjects' attention to the words, which led, in turn, to increases in perceived duration and memory. This explanation complements Meyer and Maguire's (1979) finding that the visual persistence of sine-wave gratings increases as a function of spatial frequency. The present results suggest that visual persistence is positively related to temporal frequency as well. An alternative explanation of these findings is the "contextual change" hypothesis proposed by Block and Reed (1978).

\section{REFERENCE NOTE}

1. Gouse, A. S., Polzella, D. J., Biers, D. W., \& Bower, S. M. Memory as a function of perceived duration of the retention interval. Paper presented at the meeting of the American Psychological Association, Toronto, September 1978.

\section{REFERENCES}

Avant, L. L., Lyman, P. J., \& Antes, J. Effects of stimulus familiarity upon judged visual duration. Perception \& Psychophysics, 1975, 17, 253-262.

BLOCK, R. A. Memory and the experience of duration in retrospect. Memory \& Cognition, 1974, 2, 153-160.

Block, R. A., \& ReED, M. A. Remembered duration: Evidence for a contextual-change hypothesis. Journal of Experimental Psychology: Human Learning and Memory, 1978, 4, 656-665.

Hicks, R. E., Miller, G. W., \& Kinsbourne, M. Prospective and retrospective judgments of time as a function of amount of information processed. American Journal of Psychology, 1976, 89, 719-730. 
Krauss, H. H., Katzell, R., \& Krauss, B. J. Effect of hypnotic time distortion upon free-recall learning. Journal of Abnormal Psychology, 1974, 83, 140-144.

Meyer, G. E., \& Maguire, W. M. The effects of bar width and spatial frequency-specific adaptation on visual persistence. Bulletin of the Psychonomic Society, 1979, 14, 64-66.

Miller, G. W., Hicks, R. E., \& Willette, M. E. Effects of concurrent verbal rehearsal and temporal set upon judgments of temporal duration. Acta Psychologica, 1978, 42, 173-179.

Pomerantz, J. R., Goldberg, D. M., Golder, P. S., \& TETEWSKY, S. Subjective contours can facilitate performance in a reaction-time task. Perception \& Psychophysics, 1981, 29, 605-611.

Schiffman, H. R., \& Bовко, D. J. Preference in linear partitioning: The golden section reexamined. Perception \& Psychophysics, 1978, 24, 102-103.

Thomas, E. A. C., \& Cantor, N. E. Simultaneous time and size perception. Perception \& Psychophysics, 1976, 19, 353-360.

UNDERWOOD, G. Attention and the perception of duration during encoding and retrieval. Perception, 1975, 4, 291-296.

(Received for publication August 2, 1982.) 